\title{
Pure-tone perception and ear advantages in dichotic listening
}

\author{
GINA GEFFEN and NICHOLAS REYNOLDS \\ Psychology Discipline and Centre for Neuroscience, Flinders University of South Australia \\ Bedford Park, South Australia 5042, Australia
}

\begin{abstract}
A same-different matching task was used to investigate how subjects perceived a dichotic pair of pure tones. Pairs of stimulus tones in four frequency ranges (center frequencies of 400 $1,700 \mathrm{~Hz}$ ), with separations between 40 and $400 \mathrm{~Hz}$, were tested. Five types of test tones were matched to the stimulus pair: the stimulus pair presented again (control) or crossed over (same tones, different ears), the geometric mean of the two tones, or a binaural tone of the low or high tone of the pair. In the lowest frequency range and the highest with maximum separation, the crossed-over test tones were perceived as different from the same stimulus tones. A bias for perceiving the higher tone of a pair was evident in the frequency ranges with separations of 40 $200 \mathrm{~Hz}$. In the lowest frequency range, the bias was for perceiving the higher tone in the right ear. This restricted ear advantage in the perception of pure tones was not significantly related to the right-ear advantage in dichotic word monitoring.
\end{abstract}

A common finding in speech perception research is that the speech signal contains redundant acoustical information. This has been amply demonstrated by the ability of researchers to "paint" their own spectrograms, which bear little resemblance to actual speech spectrograms but carry sufficient information to allow for the perception of speech content (Liberman, Cooper, Shankweiler, \& StuddertKennedy, 1967). Several information processing models have implied the existence of filtering mechanisms at the input stages of an information channel (Broadbent, 1971), and it may be hypothesized that some form of filtering takes place in the auditory system to separate complex signals into relevant and irrelevant components.

One method of ascertaining what remains of the signal after it has been processed is to present a complex signal followed by a component of the signal and to ask the subject whether the two inputs were the same or different. If the subject says that the inputs were the same, it is likely that the part of the original stimulus not included in the matching stimulus was filtered out, assuming that the subject does not also match what was supposedly filtered out to the original stimulus. This is the method employed in the present study. Only two input stimuli were used (both being pure tones), and determinations were made as to which stimulus dominated the percept. To offset any interactions of the two stimuli along the basilar membrane, stimuli were presented dichotically (i.e., a different stimulus to each ear) and the matching

This study was supported by an ARGC grant to Gina Geffen. We are grateful to Kustas Tiivas for software development on the tone perception task. stimuli were presented binaurally (one of the two components of the original stimulus presented to both ears).

This method allows for the testing of two possible types of dominance, ear or stimulus dominance (or some combination of the two). Several studies have examined ear differences in the perception of dichotic pure-tone stimuli. Deutsch $(1974,1975 a, 1975 b$, 1978) found a tendency for subjects to lateralize to one ear (mostly the right) the higher pitched component of a repeating signal that continuously interchanged between ears. Efron and Yund (1974) found that there was a strong ear dominance for pitch but not for loudness. Their subjects reported the pitch presented to one ear (masking the other), while attributing the percept to the ear receiving the louder signal. Deutsch (1980) looked at repeating signal ear dominance in terms of the components making up the repeating signal. She found that when the ear received the same frequencies continually (e.g., $400 \mathrm{~Hz}$ to the left ear and $800 \mathrm{~Hz}$ to the right, followed by a reversal of this in a continuing sequence), ear dominance was evidenced, whereas if a different set of frequencies followed the original set (while maintaining the high-low contrast at the two ears), the ear dominance relationship was no longer evidenced. Yund and Efron (1976) found no correlation between the ear advantage on a tonal task and a dichotic consonant-vowel task for American-English speakers, speakers of a tonal language (Thai), or musicians. These studies suggest that there is probably more than one type of ear dominance.

Stimulus dominance for pure tones has also been investigated. The adjustment of a binaural chord to match a dichotic stimulus chord produces a bias to- 
ward the higher pitched component of the dichotic chord (Efron \& Yund, 1976). Von Békésy (1963) also found a bias favoring the higher pitched member of a dichotic stimulus pair by asking subjects to report lateralization of the sound image. Subjects invariably reported that the sound image was lateralized toward the higher pitched tone. In summary, there are ear differences in tonal perception, and the higher frequency member of a dichotic stimulus pair appears to dominate the percept. However, the interaction of stimulus and ear dominance has not previously been investigated in a single study.

The presentation of two different tones, one to each ear, could produce a percept including both (separation), one (masking), or some combination of them (fusion). Since the present study sought to investigate stimulus and ear dominance, stimuli that were most likely to mask one another were selected on the basis of previous studies that had examined the fusion of pure tones (Odenthal, 1963; van den Brink, Sintnicolaas, \& van Stam, 1976). The curves for the difference in frequency between two stimulus tones that generate a fused percept representing the arithmetic mean of the stimuli may be seen in Figure 1. It is suggested that the use of stimuli outside the regions of fusion would produce masking. Figure 1 also shows the critical bands given by Scharf (1972), which are defined as that region of noise that masks a signal of a given center frequency. Outside this region there is no substantive basis for meaningful combination of tones, and forced choices would hypothetically reflect biases in subjects unrelated to actual processing considerations. The points used as stimuli in the present study (all but one of which lie outside the fusion range and inside the critical bandwidths) are also given in Figure 1. They were selected because they lie on "flat" points along the equiloudness contours given by Scharf (1972), thereby eliminating the need to manipulate intensity. Point 4 represents the tone pair $(1,500$ and $1,900 \mathrm{~Hz})$ used by Efron and Yund (1974).

This paper is concerned with the relative importance of different frequency components of a signal in relation to ear of presentation. Specific questions were: Is there a bias toward the higher pitched tone (Efron \& Yund, 1976; von Békésy, 1963) across several frequency ranges? Does the right-ear advantage commonly found in speech perception (e.g., Geffen, Traub, \& Stierman, 1978; Kimura, 1961a, 1961b) occur in tonal perception? If so, are the two types of ear differences related?

\section{METHOD}

\section{Subjects}

Twelve males and 12 females, with ages ranging from 17 to 28 years (mean age $=18$ years), were tested. Twenty-one subjects were right-handed as assessed by the six primary questions of Annett's (1970) handedness questionaire, while three subjects

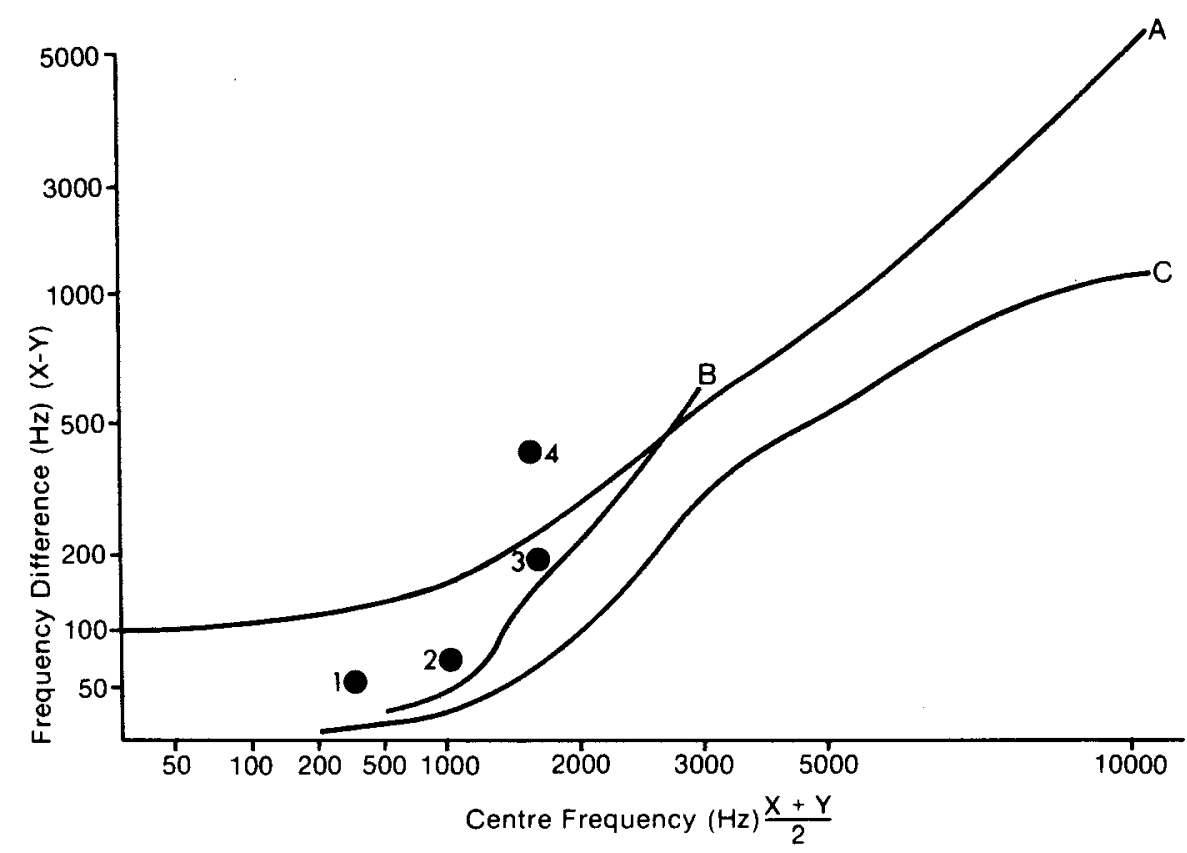

Figure 1. The frequency difference between a pair of pure tones ( $x$ and $y$ ) as a function of the arithmetic mean for tone pairs used in this study $(1,2,3,4)$. Curve $A$ represents the region of noise that masks a signal of a given center frequency (Scharf, 1972). Curve B (van den Brink, Sintnicolass, \& van Stam, 1976) and Curve C (Odenthal, 1963) demonstrate previous findings of fusion of the tone pair. 
answered 1/6 questions as left or either hand. Four right-handers and one "mixed-hander" reported familial sinistrality (see note to Table 2 for ear advantages). All subjects used their right hands for writing. None of the subjects reported having hearing difficulties. They were all psychology undergraduates who had volunteered and were paid a nominal sum for their involvement.

\section{Apparatus \\ Subjects were tested on-line to a PDP-11/10 minicomputer that controlled two tone generators. The tones were controlled through a stereo amplifier (with volumes checked for compatibility be- tween channels on meters), and a two-channel 1-dB step attenu- ator. Tones were presented to subjects through TDH-39 matched headphones in Maico auraldomes. A two-key response box was} used to provide response information to the computer.

\section{Procedure}

The pure-tone stimulus pairs were: $380-420 \mathrm{~Hz}, 940-1,060 \mathrm{~Hz}$, $1,500-1,700 \mathrm{~Hz}, 1,500-1,900 \mathrm{~Hz}$. Subjects were presented with one of each pair to each ear simultaneously (dichotic presentation) followed by a dichotic control or binaural test pair (see Table 1). The required response was a "same" or "different" judgment conveyed by pressing the appropriate key on the response box. A red lightemitting diode (1.e.d.) mounted at eye level on a black screen $30 \mathrm{~cm}$ from the seated subject was the warning signal and served to maintain visual fixation and hence to control attention. Each trial involved, first, the l.e.d.'s being illuminated. After $320 \mathrm{msec}$, the pair of stimulus tones occurred, which were played at $65 \mathrm{~dB}$ (Phillips sound-level meter, C scale) and lasted for $320 \mathrm{msec}$. After $900 \mathrm{msec}$, the test tones occurred, which were played for the same duration $(320 \mathrm{msec})$ and intensity $(65 \mathrm{~dB})$. The offset of the test tones coincided with the offset of the l.e.d., and $2 \mathrm{sec}$ was allowed for a response before the next trial began. The index and middle fingers of one hand were comfortably placed on the keys in a vertical rather than a left-right orientation to avoid response-induced lateralization of inputs. The hand that was used and the finger that indicated a "same" response were counterbalanced between subjects.

There were $\mathbf{8 0 0}$ trials altogether. Each stimulus pair was presented 200 times, 100 times with the low tone in the left ear and 100 times with the low tone in the right ear. The five different test tones were presented 20 times to each ear for each stimulus pair. The 800 trials were randomized and presented in four blocks of 200 each, with a 3-min rest period in between. The room used for testing was darkened and shielded from extraneous noises. Headphones were reversed after each test block to control for any possible residual channel difference. Prior to the test trials, a block of 40 practice trials was presented to subjects to familiarize them with their task. Subjects were instructed to press one key if they thought the test pair of tones was the same as the stimulus pair and the other key if they thought the pairs differed. Fast, accurate responses were encouraged during the practice trials. The entire test session lasted for about $1 \mathrm{~h}$.

\section{Dichotic Monitoring Task}

This task has been previously validated for predicting hemispheric dominance for speech perception (Geffen et al., 1978) and

Table 1

\begin{tabular}{lll}
\hline \multicolumn{1}{c}{ Test Tones } & \multicolumn{1}{c}{ Ear 1 } & \multicolumn{1}{c}{ Ear 2 } \\
\hline Low Binaural & Low & Low \\
High Binaural & High & High \\
Control & Low & High \\
Crossover Control & High & Low \\
Geometric Mean & $\sqrt{\text { High * Low }}$ & $\sqrt{\text { High * Low }}$ \\
\hline
\end{tabular}

Note-Stimulus tones (low for Ear 1 and high for Ear 2) for four different frequency ranges were presented in pairs (see text) for 320 msec and followed by one of five test tones. is reliable (Geffen \& Caudrey, 1981). The details of tape construction may be found in Sexton and Geffen (1981). Five lists of 168 word pairs were presented at one pair per $750 \mathrm{msec}$. There were two target words per list, and subjects had to respond by pressing a response key if they heard either target word in either ear. The target words for the practice list were "crane" and "prod," and for the test lists they were "black" and "great" (two consecutive lists) and "glow" and "clap" (two consecutive lists). There were 10 target words (five of each type) per channel per list and 10 phonemically similar distractors.

Subjects listened to stimuli through the same headphones and at the same intensity as that used in the tonal perception task. Subjects responded to target words by pressing a button on an FM response panel that was recorded directly onto channel 4 of the stimulus tape. Analysis was carried out by a PDP-11/10 minicomputer utilizing both the pacing tones and the response tones on channels 3 and 4 , respectively, of the tape.

Subjects were tested in a separate session after participation in the tonal perception task. The ear receiving channel 1 and the hand used to respond for each list were randomized both between and within subjects. Attention was divided between ears, and subjects were requested to respond to targets whenever they were heard. A card containing the target pair was fixed to the back of the tape recorder, and eye movements were kept to a minimum by requiring subjects to restrict their gaze to the card in front of them.

\section{RESULTS}

An ANOVA was performed on the proportion of "same" responses collapsed across ears with the factors of sex (2), test tone (5), and frequency range (4), the last two factors being repeated measures. There was a highly significant main effect of test tone $[F(4,88)$ $=114.2, \mathrm{p}<.001$ ]. Post hoc tests [least significant differences (LSD); Keppel, 1973, p.135] showed that all test tones except the low binaural and geometric mean differed significantly from one another (see Figure 2). Since there was no involvement of the low binaural or the geometric mean test tones in any further interactions, and due to the small percentage of "same" responses to these test tones, these were analyzed no further.

Females responded "same" more often than did males $[F(1,22)=4.15, p<.05]$; however, this was shown by post hoc analyses (LSD) to be true only for the high binaural test tone; the sex $\times$ test tone interaction was significant $[F(4,88)=3.08, p<.05$; see Figure 3].

There was a significant main effect of frequency range $[F(3,66)=10.09, p<.001]$ modified by a significant two-way interaction between test tone and frequency range $[F(12,264)=5.3, p<.001]$. Figure 2 shows that only the high binaural and the crossover control test tones showed significant differences across frequency ranges, with a larger proportion of "same" responses for both of these test tones for the $940-1,060-\mathrm{Hz}$ and the $1,500-1,700-\mathrm{Hz}$ stimulus pairs than for the $380-420-\mathrm{Hz}$ and the $1,500-1,900-\mathrm{Hz}$ pairs. At this stage, a new factor called ear of presentation (of high tone in the stimulus pair) was introduced in an analysis of the proportion of "same" re- 


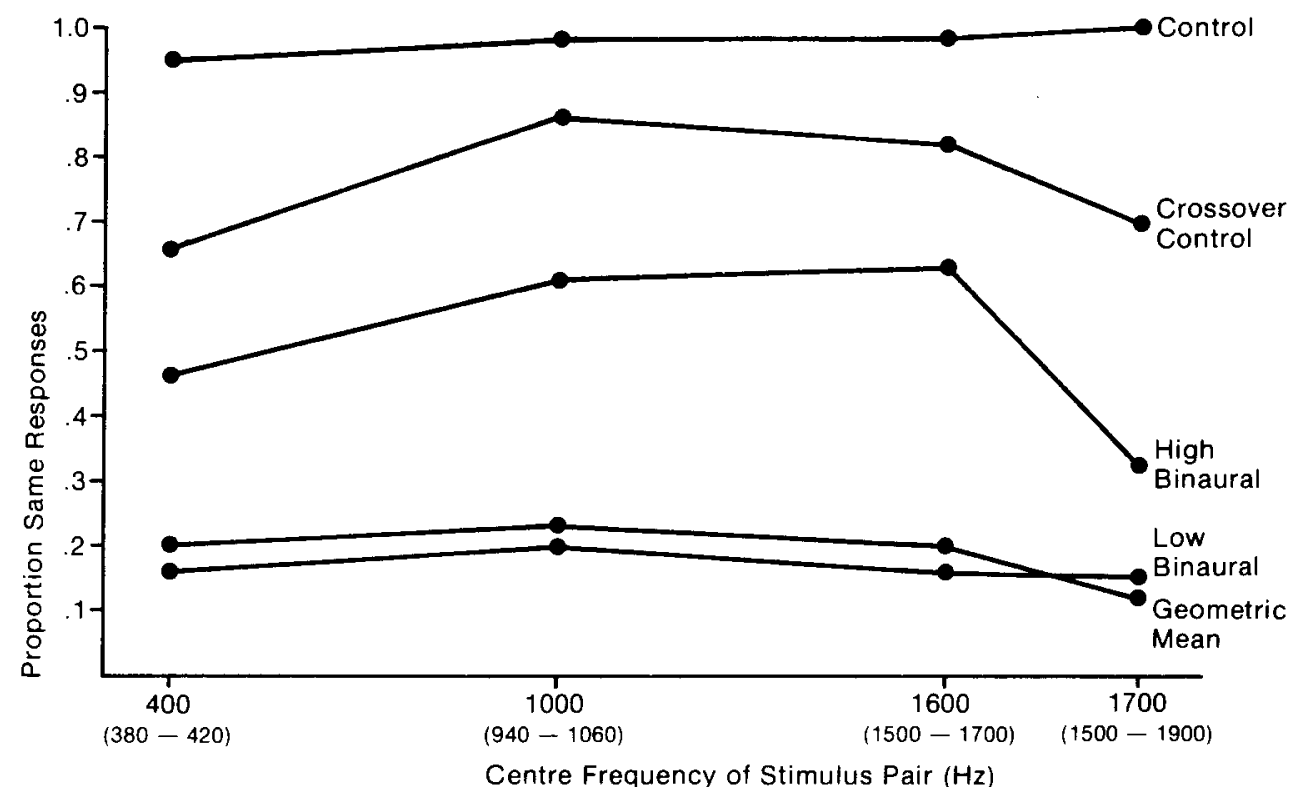

Figure 2. Proportion of "same"' responses for the five test tones as a function of center frequency of the four stimulus pairs.

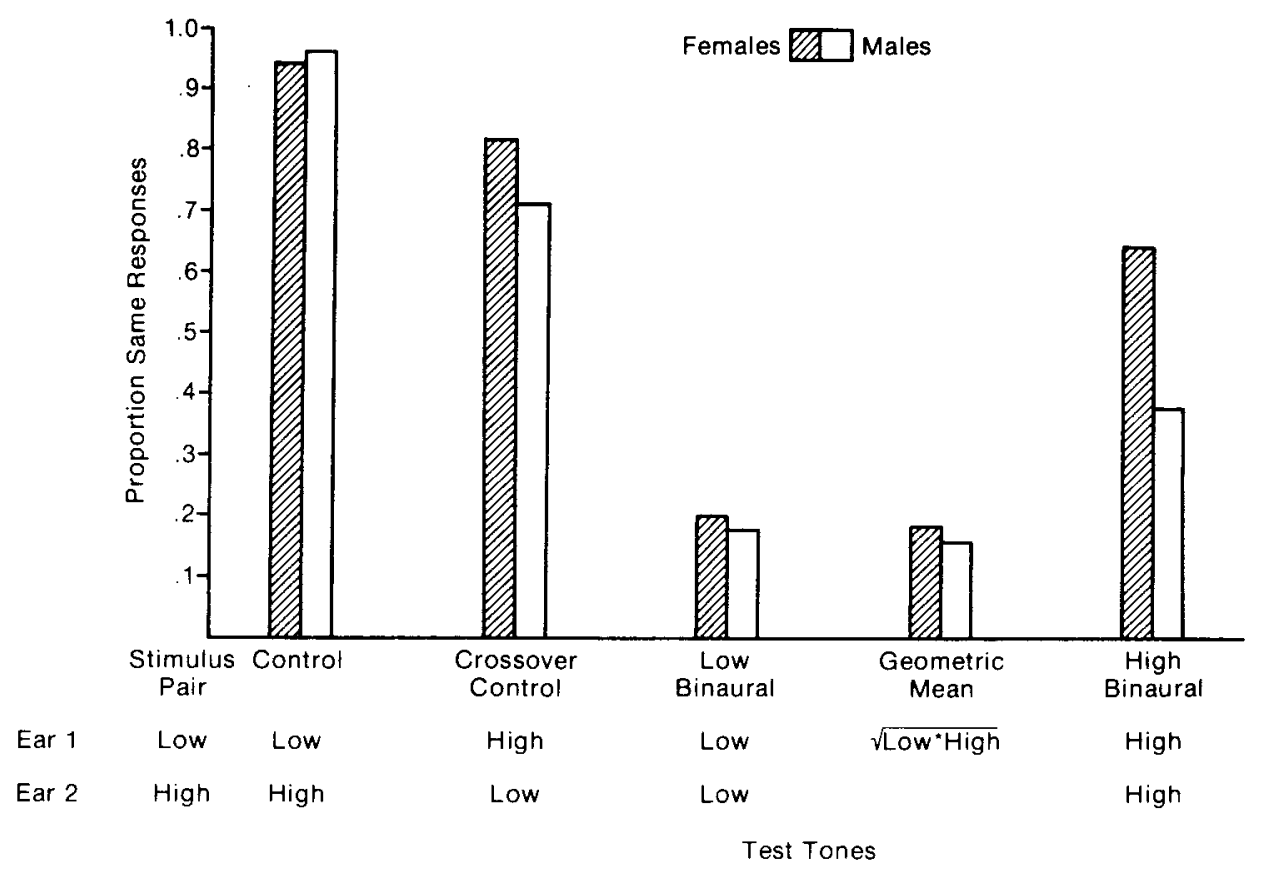

Figure 3. Proportion of "same" responses as a function of test tone for males $(n=12)$ and females $(n=12)$, showing the sex $\times$ test tone interaction. 
sponses to the high binaural test tone to ascertain whether the presence of, for example, a bias toward the right ear occurred only when the higher pitched of the two tones was presented to it. This could possibly cause the falloff in the proportion of "same" responses to the crossover control test tones. Accordingly, a three-way ANOVA with the factors ear (2), sex (2), and frequency range (4) was performed on the proportion of "same" responses to the high binaural test tones. Significant main effects of frequency range $[F(3,33)=11.61, p<.001]$ and sex $[F(1,11)=$ $11.12, p<.001]$ were found, both of which have already been discussed. The new factor, ear, showed no significant main effect and no significant interaction with sex; however, the interaction between ear and frequency range was significant $[F(3,33)=6.85$, $\mathrm{p}<.001$; see Figure 4).

LSD post hoc tests showed that the only significant ear difference was obtained when a pair of tones, $380 \mathrm{~Hz}$ in one ear and $420 \mathrm{~Hz}$ in the other, was followed by a test tone of $420 \mathrm{~Hz}$ to both ears. Subjects reported these two events to be "same" more often when the higher tone of the stimulus pair $(420 \mathrm{~Hz})$ was presented to their right rather than to their left ears. The opposite ear difference obtained with the 940-1,060-Hz pair approached, but did not reach, significance $(.05<\mathrm{p}<.01)$. The three-way interaction of ear $\times \operatorname{sex} \times$ frequency range was not significant $(F<1)$.

To examine whether the right-ear bias for the high binaural test tone in the low-frequency range was re- lated to the right-ear advantage (REA) shown in the dichotic monitoring task, the number of subjects shown as left-, right-, or no-ear advantages on each task was tallied (see Table 2). The relationship was not significant (Kendall's tau, $\mathrm{p}>.05$ ).

With the degree of variability of "same" and "different" responses to the test tones, the use of an ANOVA on RT measures was untenable. Means of median RTs to the various test tones, assuming that faster responses reflect greater certainty in responses (Krueger, 1978), showed a pattern similar to the proportion of "same" responses for each test tone (see Figure 5).

\section{DISCUSSION}

Responses to the control test tones were fast and accurate, indicating that the task was not difficult. When the same pair of test and stimulus tones was presented, but to opposite ears (crossover control), the proportion of "same" responses was significantly reduced when the frequency range was low $(380-420 \mathrm{~Hz})$ and when the frequency separation was large $(1,500-1,900 \mathrm{~Hz})$. Either one tone in one ear dominated the perception or the change in orientation was perceived. The inclusion of both low and high binaural test tones enabled us to sort out which ear and what tone. The low binaural test tone produced very few "same" responses; thus, it is highly unlikely that the low tone of the stimulus pair ever dominated the subject's perception. The proportion

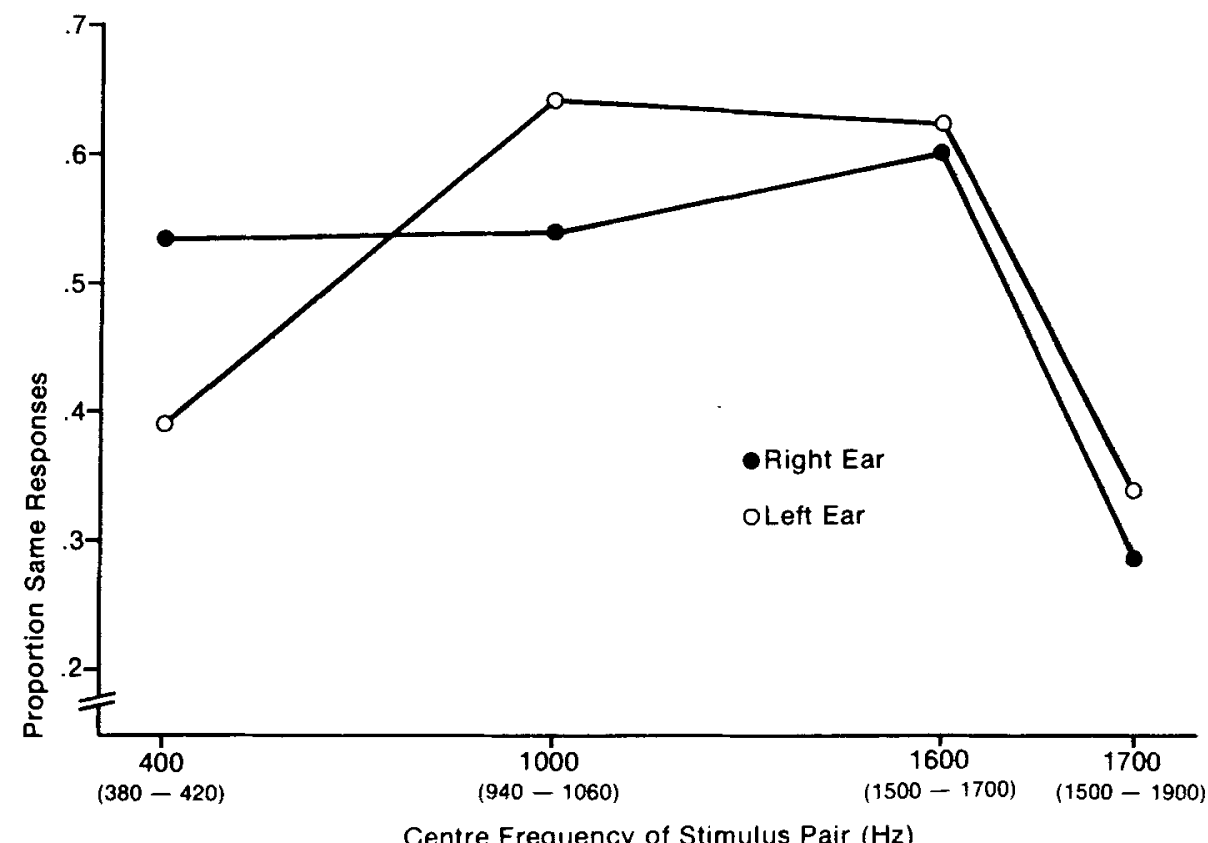

Figure 4. Proportion of "same" responses as a function of center frequency of stimulus pairs for the high binaural test tone, showing the ear $x$ frequency range interaction. The ear receiving the high tone of the stimulus pair is designated as left or right. 
Table 2

Number of Subjects Showing Ear Preferences in the Dichotic Word Monitoring Task and the High Binaural Test Tones for the Low-Frequency Stimulus Pair (380-420 Hz)

\begin{tabular}{ccccc} 
& \multicolumn{4}{c}{ Test-Tone Ear Preference } \\
\cline { 2 - 5 } Preech Ear & Left & None & Right & Total \\
\hline Left & 1 & 2 & 2 & 5 \\
None & 0 & 2 & 0 & 2 \\
Right & 4 & 4 & 9 & 17 \\
Total & 5 & 8 & 11 & 24 \\
\hline
\end{tabular}

Note-Neither mixed handedness nor familiar sinistrality predicted ear preference for dichotic speech.

of "same" responses to the geometric mean test tone similarly indicates that subjects did not perceive the stimulus pair as a single, fused average tone.

The high binaural test tones were perceived to be the same as the stimulus pair on more than $50 \%$ of the occasions, except for the $1,500-1,900-\mathrm{Hz}$ pair. With the latter pair, subjects reported always hearing two tones, and it is likely that a "different" response was made to high binaural test tones on the basis of perceiving one vs. two tones and to the crossover control of this pair as a perception of change in orientation. The apparent dominance of the higher tone of the pair in the percept across the other three ranges fits in well with previous research indicating dominance of higher tones differentially utilizing lateralization (von Békésy, 1963), adjustment of a binaural chord (Efron \& Yund, 1976), and continuous presentation of a scale sequence (Deutsch, 1975a, 1975b).

At the lowest frequency range $(380-420 \mathrm{~Hz})$, the bias for perceiving the higher tone occurred only when it was presented to the right ear. This finding extends those of Deutsch (1974) concerning pitch perception of repeating dichotic tone pairs that were in octave relationship to each other. Deutsch presented tones of 400 and $800 \mathrm{~Hz}$ that alternated from ear to ear such that, when the $400-\mathrm{Hz}$ tone was in the left ear, the $800-\mathrm{Hz}$ tone was in the right ear, and vice versa. Most right-handed subjects in this condition perceived the sequence as a single high tone in the right ear followed by a single low tone in the left ear. This was later shown by Deutsch (1975a) to be due to two factors: (1) the perception of the sequence of pitches presented to the right ear, and (2) the lateralization of each tone toward the ear receiving the higher frequency. The present findings show a right-ear bias for the higher tone in the $320-420-\mathrm{Hz}$ pair that were presented neither in a repeating sequence nor in octave relationship to each other. This suggests that Deutsch's finding may be more general, although apparently only in the lower frequency range.

Further experiments are required to determine whether the ear-tone dominance is due to the frequency separation or, as is indicated by the communality between the present findings and those of Deutsch $(1974,1975 a)$, to the frequency range. The bias for perceiving the high tone in the right ear with the lowest frequency range would explain the significantly reduced proportion of "same" responses to the crossover control pair of test tones in this frequency range $(380-420 \mathrm{~Hz})$.

Yund and Efron's (1977) model of pitch perception suggests that there is a central combination of monaural inputs according to weighting of inputs from each ear, differential sensitivity of the two ears, or

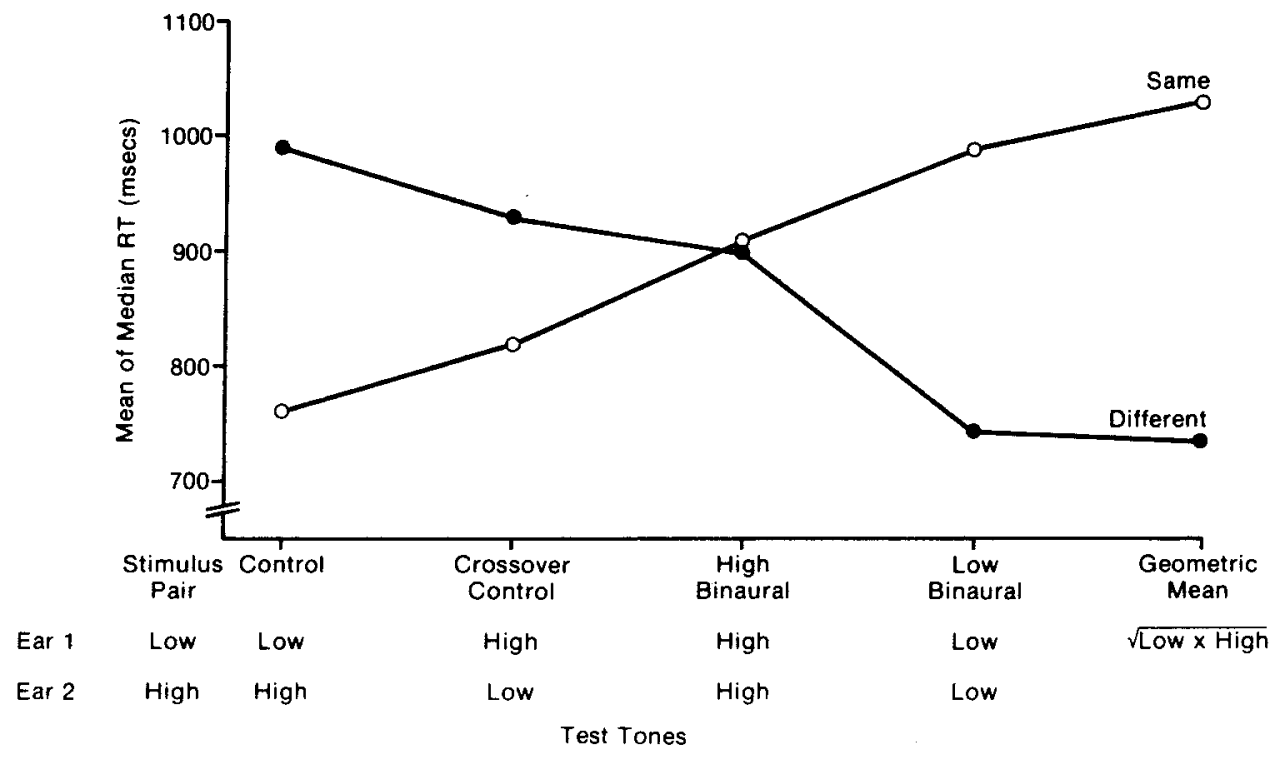

Figure 5. Means of median reaction times as a function of test tones for "same" and "different" responses. 
dissimilarity between the ears in intensity responses. Deutsch (1980) found that similar effects could be obtained using speakers placed differentially in auditory space and suggested that tone combinations could occur in spatial locations as well as frequency values. The findings of the present study indicate the need to investigate both relative frequency and spatial locations to determine their interaction.

The tonal ear dominance was not found to be significantly related to the right-ear advantage for speech perception, supporting the findings of Yund and Efron (1976). However, a parallel to the finding of a bias for perceiving higher tones may be found in the work of Liberman et al. (1967), who found that the carrier frequencies in speech are lower in pitch than the formants that provide highly relevant information. Some attention may be paid to the fundamental frequency (or lower frequencies) to allow speaker identification (Wolf, 1977), but such monitoring is infrequent compared with that of information characters (higher frequencies). The bias of females for perceiving the higher tone of the stimulus pair requires replication. The greater accuracy of males in pitch perception may be related to their pubertal experience of voice changes.

\section{REFERENCES}

AnnetT, M. A classification of hand preference by association analysis. British Journal of Psychology, 1970, 61, 303-321.

Broadbent, D. E. Decision and stress. London: Academic Press, 1971.

DeUtSch, D. An auditory illusion. Nature, 1974, 251, 307-309.

Deutsch, D. Musical illusions. Scientific American, 1975, 223, 92-104. (a)

DeUTsch, D. Two-channel listening to musical scales. Journal of the Acoustical Society of America, 1975, 57, 1156-1160. (b)

DeuTsch, $D$. Lateralization by frequency for repeating sequences of dichotic 400- and $800-\mathrm{Hz}$ tones. Journal of the Acoustical Society of America, 1978, 63, 184-186.

De UTSCH, D. Ear dominance and sequential interactions. Journal of the Acoustical Society of America, 1980, 67, 220-228.

EFron, R., \& Yund, E. N. Dichotic competition of simultaneous tone bursts of different frequency. I. Dissociation of pitch from lateralization and loudness. Neuropsychologia, 1974, 12, 249 256.

EFron, R., \& YUND, E. W. Ear dominance and intensity independence in the perception of dichotic chords. Journal of the Acoustical Society of America, 1976, 59, 889-898.

Geffen, G., \& Caudrey, D. Reliability and validity of the dichotic monitoring test for language laterality. Neuropsychologia, 1981, 19, 413-423.

Geffen, G., Traub, E., \& Stierman, I. Language laterality as assessed by unilateral E.C.T. and dichotic monitoring. Journal of Neurology, Neurosurgery and Psychiatry, 1978, 41, 354-360.

KE PPEL, G. Design and analysis. Englewood Cliffs, N.J: PrenticeHall, 1973.

KimurA, D. Some effects of temporal-lobe damage on auditory perception. Canadian Journal of Psychology, 1961, 15, 156165. (a)

Kimura, D. Cerebral dominance and the perception of verbal stimuli. Canadian Journal of Psychology, 1961, 15, 166-171. (b)

Krueger, L. E. A theory of perceptual matching. Psychological Review, 1978, 85, 278-304.

Liberman, A. M., Cooper, F. S., Shankweiler, D. P., \& Studde rT-Kennedy, M. Perception of the speech code. Psychological Review, 1967, 74, 431-461.

Odenthal, D. W. Perception and neural representation of simultaneous dichotic pure tone stimuli. Acta Physiologica and Pharmacologica Neerlandica, 1963, 12, 453-496.

Sch ARF, B. Critical bands. In J. V. Tobias (Ed.), Foundations of modern auditory theory (Vol. 2). New York: Academic Press, 1972.

Sexton, M. A., \& Geffen, G. Phonological fusion in dichotic monitoring. Journal of Experimental Psychology: Human Perception and Performance, 1981, 7, 422-429.

van den Brink, G., Sintinicolaas, K., \& van Stam, W. S. Dichotic pitch fusion. Journal of the Acoustical Society of America, 1976, 59, 1471-1476.

voN BÉKÉSY, G. Three experiments concerned with pitch perception. Journal of the Acoustical Society of America, 1963, 35, 602-606.

WoLF, C. G. The processing of fundamental frequency in a dichotic matching task. Brain and Language, 1977, 4, 70-77.

YunD, E. W., \& EFron, R. Dichotic competition of simultaneous tone-bursts of different frequency: IV. Correlation with dichotic competition of speech signals. Brain and Language, 1976, 3, 246-254.

Yund, E. W., \& Erron, R. Model for the relative salience of the pitch and pure tones presented dichotically. Journal of the Acoustical Society of America, 1977, 62, 607-617.

(Manuscript received March 30, 1981; revision accepted for publication October 4,1981 .) 